\title{
The Relative Rates of Urea and Water Permeation in the Distal Nephron of the Intact Kidney*
}

\author{
JoHN R. JAENIKE \\ (From the Department of Medicine, University of Rochester School of Medicine, \\ Rochester, N. Y.)
}

Present evidence indicates that water and other molecules insoluble in lipid permeate biological membranes by passing through aqueous channels or pores in the membrane. Characteristic of this process is the ability of the membrane to distinguish between permeating substances on the basis of molecular size or configuration. In the vasopressin-sensitive amphibian epithelial membranes, this characteristic is illustrated by the difference in permeability to water and to urea, in the absence of vasopressin (1). In the presence of hormone the discrepancy between the permeability coefficients of these molecules is reduced, presumably coincident to an increase in membrane pore size induced by the hormone (1). These observations illustrate the principle that the degree of a membrane's permeability may be evaluated by determining the relative rates of permeation of two different molecules. I have applied this principle to studies on the distal nephron of the intact kidney, a system in which current methodology does not permit the direct determination of precise flux rates or permeability coefficients.

Previous work has demonstrated that the permeability to urea of the collecting duct of the dog kidney is increased by the action of vasopressin (2). This observation, obtained from studies in the intact animal, has been confirmed by the experiments of Gardner and Maffly, utilizing an in vitro perfusion of the rat renal papilla (3). It has been postulated that graded degrees of permeability of the distal tubular system will be manifested by comparing the permeation of urea to that of water. Earlier experiments have demonstrated that when a maximal amount of vasopressin is

* Submitted for publication July 16, 1963 ; accepted September 19, 1963.

This investigation was supported by research grant A-4393 from the National Institute of Arthritis and Metabolic Diseases, U. S. Public Health Service, Bethesda, Md. given during water diuresis, there occurs initially a rise in urinary osmolality, which is entirely or largely accounted for by an increase in the urinary concentration of nonurea solutes, primarily electrolytes (4). During this initial transient state, there is little or no increase in the urinary concentration of urea. If this phenomenon is explained by a high degree of permeability of the distal nephron to urea, in the presence of large amounts of vasopressin, it should be altered during experiments performed at varying degrees of tubular permeability. This hypothesis has been tested in the present study. The results provide evidence relating to the mechanism of urea concentration in the urine and in the renal medulla and suggest a method for evaluating distal tubular permeability in the kidney of the intact animal.

\section{Methods}

All studies were conducted in two unanesthetized female dogs: $\operatorname{dog} \mathrm{T}$ weighed $18 \mathrm{~kg} ; \operatorname{dog} \mathrm{A}, 15 \mathrm{~kg}$. Experiments were performed in the morning. The dogs fasted overnight but were allowed free access to water. After insertion of a Foley catheter, a standard water load, amounting to approximately $4 \%$ of the body weight, was given intravenously in the form of a $2.5 \%$ glucose solution. Thereafter, throughout the course of the experiment, positive water balance was maintained at the initial level by the infusion of the same solution via a constant infusion pump. No allowance was made for insensible water loss. After establishment of a water diuresis at a relatively constant urinary flow rate, samples were collected during 2 to 3 control periods. Immediately thereafter vasopressin was given in a single iv injection. Urine specimens were collected at frequent intervals over the ensuing 15 to 30 minutes. Bladder emptying was accomplished by the injection of air, followed by manual compression. No sustaining infusion of hormone was given. A highly purified form of lysine vasopressin ${ }^{1}$ was used in all experiments.

The response to three different dose levels of vasopressin, 10, 30, and $300 \mathrm{mU}$, was evaluated. In some experiments the response to two different dosages was

1 Supplied by Sandoz Pharmaceuticals, Hanover, N. J. 
assessed. In these studies the smaller dose was given first; the second dose was administered after the effects of the initial injection had disappeared, as evidenced by the re-establishment of water diuresis. Data obtained from the second part of such studies were not discernible from those obtained when the same dose of vasopressin was given as the only test dose.

The concentrations of inulin, urea, and total solute in plasma and urine were determined by methods previously outlined (4).

\section{Results}

Thirty-six experiments have been performed in two dogs, under standard conditions of water diuresis, utilizing dosage levels of 10,30 , and 300 $\mathrm{mU}$ of vasopressin. One experiment at each level of vasopressin is depicted in Figures 1 and 2, on dogs $\mathrm{T}$ and $\mathrm{A}$, respectively. The detailed data from the three experiments on $\operatorname{dog} \mathrm{T}$ are contained in Table I. Figures 1 and 2 depict the changes in the urinary concentration of urea and of nonurea solutes (NUS) in the period immediately after the injection of vasopressin. The plots are extended to the time at which a maximal NUS concentration had been achieved for that experiment.

The configuration of the concentration curves after the administration of $300 \mathrm{mU}$ of vasopressin is comparable to those previously obtained in similar experiments, in which $300 \mathrm{mU}$ of aqueous Pitressin was given and followed by a sustaining infusion of $30 \mathrm{mU}$ per $\mathrm{kg}$ of body weight per hour (4). Of particular note in the experiments utilizing $300 \mathrm{mU}$ of vasopressin is the initial rise in urinary NUS concentration occurring without an increase in the urinary urea concentration. As depicted in Figures 1 and 2, NUS concentrations greater than $300 \mathrm{mOsm}$ per $\mathrm{kg}$ were attained with

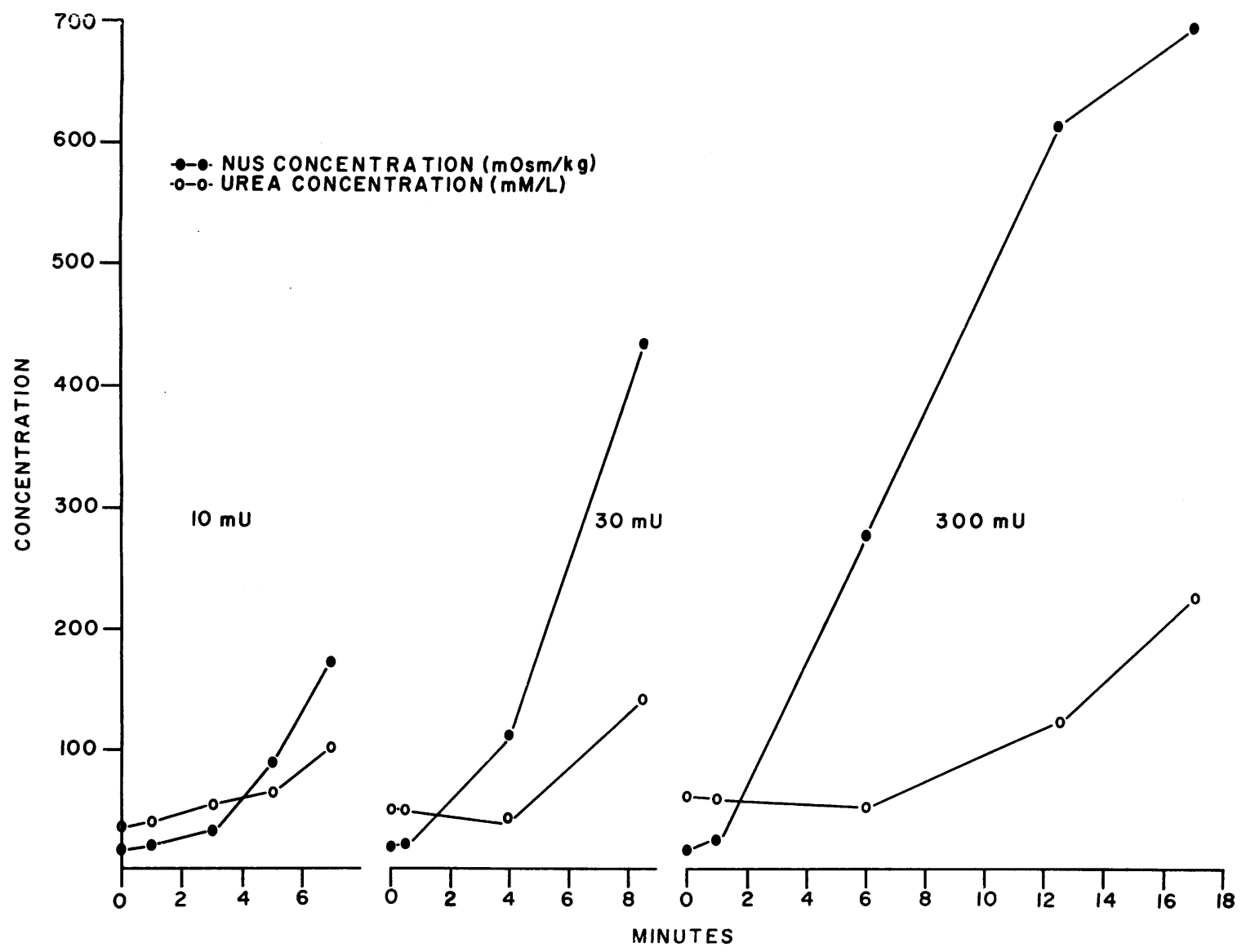

Fig. 1. Dog T. The rates of Rise of URea and nonurea solute (NUS) after injection of vasopressin at DOSAGE LEVELS OF 10, 30, AND 300 MU DURING WATER DIURESIS. In this and subsequent figures, the point at zero time represents data from the last control period. All other data are plotted at the mid-points of the collecting periods. 


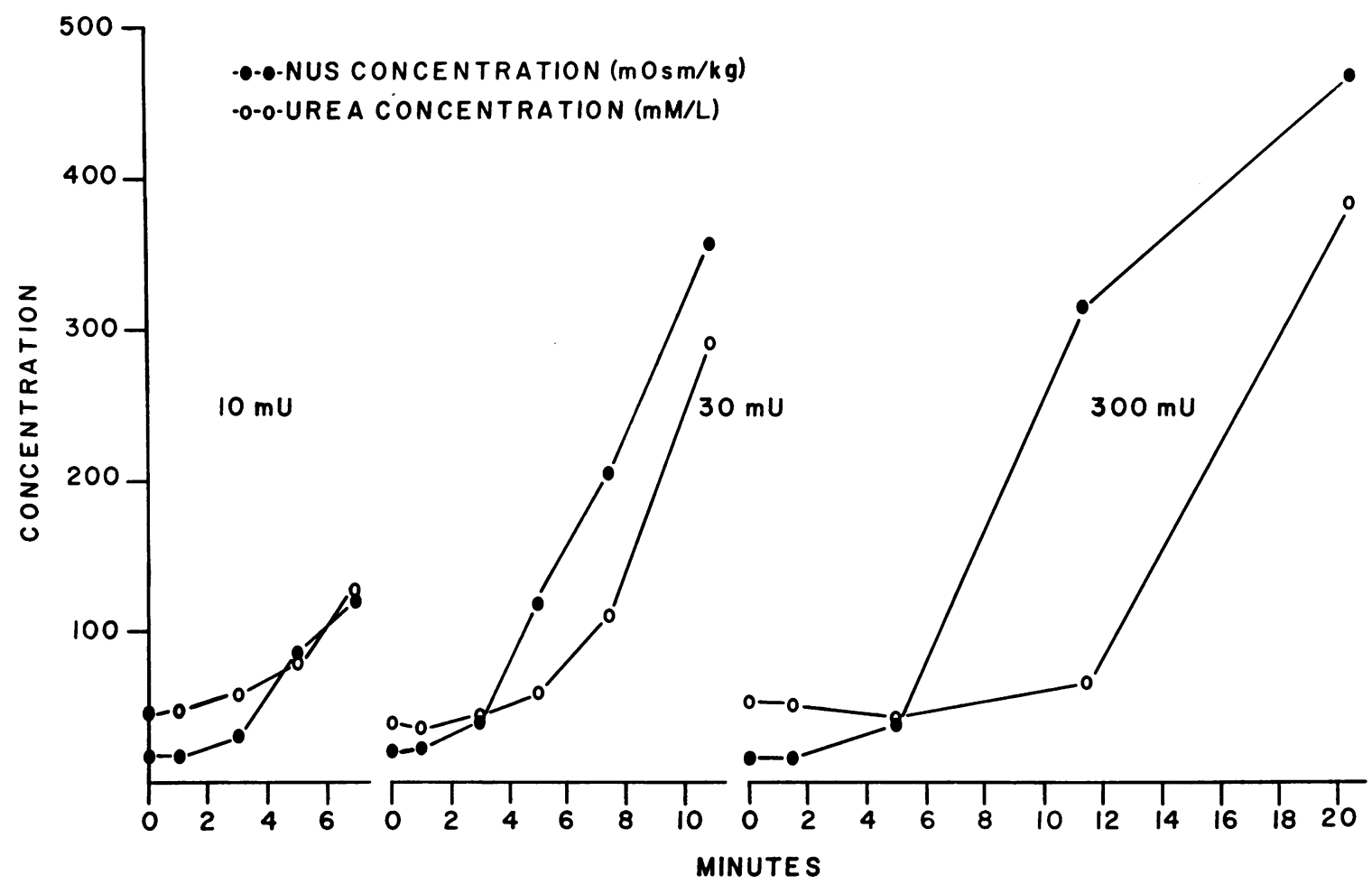

Fig. 2. Dog A. The rates of rise of urea and nonurea solute (NUS) after injection of vasopressin at DOSAGE LEVELS OF 10, 30, AND 300 MU DURING WATER DIURESIS.

little or no change in the concentration of urea. below the control level within the first 10 minutes In the majority of the experiments at this dosage after hormone administration (see Table I). level, the urea concentration decreased moderately These data indicate a great difference between

TABLE I

Dog T. Data from experiments with 10,30, and $300 \mathrm{mU}$ of vasopressin*

\begin{tabular}{|c|c|c|c|c|c|c|c|c|}
\hline Vasopressin & Time & $\begin{array}{l}\text { Urine } \\
\text { flow }\end{array}$ & Uosm & $\mathrm{U}_{\text {urea }}$ & NUS & $\begin{array}{c}\mathrm{U} / \mathrm{P} \\
\text { urea }\end{array}$ & $\begin{array}{l}\text { U/Purea } \\
\text { NUS }\end{array}$ & $\underset{\text { inulin }}{\mathrm{U} / \mathrm{P}}$ \\
\hline$m U$ & $\min$ & $m l / m i n$ & $\mathrm{mOsm} / \mathrm{kg}$ & mmoles $/ L$ & $\mathrm{mOsm} / \mathrm{kg}$ & & & \\
\hline 10 & $\begin{array}{rr}-10- & -5 \\
-5- & 0 \\
0- & 2 \\
2- & 4 \\
4- & 6 \\
6- & 8 \\
8- & 10\end{array}$ & $\begin{array}{l}4.70 \\
4.96 \\
2.95 \\
1.22 \\
0.55 \\
0.78 \\
1.11\end{array}$ & $\begin{array}{r}47 \\
50 \\
56 \\
85 \\
153 \\
274 \\
306\end{array}$ & $\begin{array}{r}34 \\
35 \\
37 \\
54 \\
64 \\
102 \\
150\end{array}$ & $\begin{array}{c}13 \\
15 \\
19 \\
31 \\
89 \\
172 \\
156\end{array}$ & $\begin{array}{r}8.0 \\
8.3 \\
8.8 \\
12.8 \\
15.1 \\
24.1 \\
35.5\end{array}$ & $\begin{array}{l}0.611 \\
0.551 \\
0.461 \\
0.412 \\
0.170 \\
0.140 \\
0.227\end{array}$ & $\begin{array}{l}14.3 \\
14.4 \\
17.1 \\
31.2 \\
67 \\
122 \\
102\end{array}$ \\
\hline 30 & $\begin{array}{rr}-10- & -5 \\
-5- & 0 \\
0- & 1 \\
1- & 7 \\
8- & 10 \\
10- & 13\end{array}$ & $\begin{array}{l}4.00 \\
4.04 \\
2.10 \\
0.10 \\
0.30 \\
0.79\end{array}$ & $\begin{array}{r}77 \\
68 \\
71 \\
155 \\
579 \\
439\end{array}$ & $\begin{array}{r}53 \\
49 \\
49 \\
43 \\
144 \\
268\end{array}$ & $\begin{array}{r}24 \\
19 \\
22 \\
112 \\
435 \\
171\end{array}$ & $\begin{array}{r}12.0 \\
11.2 \\
11.1 \\
9.7 \\
32.6 \\
60.6\end{array}$ & $\begin{array}{l}0.503 \\
0.605 \\
0.507 \\
0.086 \\
0.075 \\
0.355\end{array}$ & $\begin{array}{l}19.0 \\
17.5 \\
20.9 \\
83 \\
449 \\
121\end{array}$ \\
\hline 300 & $\begin{array}{rr}-10- & -5 \\
-5- & 0 \\
0- & 2 \\
2- & 10 \\
10- & 15 \\
15- & 19\end{array}$ & $\begin{array}{l}3.30 \\
3.40 \\
0.35 \\
0.075 \\
0.16 \\
0.17\end{array}$ & $\begin{array}{r}83 \\
77 \\
83 \\
329 \\
738 \\
922\end{array}$ & $\begin{array}{r}65 \\
61 \\
59 \\
53 \\
124 \\
227\end{array}$ & $\begin{array}{r}18 \\
16 \\
24 \\
277 \\
614 \\
695\end{array}$ & $\begin{array}{r}11.4 \\
10.6 \\
10.2 \\
9.2 \\
21.6 \\
39.5\end{array}$ & $\begin{array}{l}0.646 \\
0.663 \\
0.425 \\
0.033 \\
0.035 \\
0.057\end{array}$ & $\begin{array}{l}21.0 \\
19.7 \\
19.9 \\
365 \\
575 \\
484\end{array}$ \\
\hline
\end{tabular}

${ }^{*} \mathrm{U}=$ urinary, $\mathrm{NUS}=$ nonurea solutes, $\mathrm{U} / \mathrm{P}=$ urine to plasma concentration ratio. 
urea and NUS in their degree of permeation of the distal nephron during this time period.

In the experiments utilizing $30 \mathrm{mU}$ of vasopressin, the initial rate of rise of NUS concentration is similar to that after administration of $300 \mathrm{mU}$ (Figures 1 and 2), although a higher NUS concentration was ultimately achieved at the larger dose level. A discrepancy between the rates of rise of urea and NUS concentration is also observable at this dosage level but is less marked than that after administration of $300 \mathrm{mU}$. As the NUS concentration exceeds 200 to $300 \mathrm{mOsm}$ per $\mathrm{kg}$, the urea concentration rises to levels at least double the control values, in contrast to the pattern after $300 \mathrm{mU}$ of hormone, in which the urea concentration shows little change.

The concentration patterns following $10 \mathrm{mU}$ of vasopressin injection are in distinct contrast to those noted after larger doses. The earliest and smallest rise in NUS concentration is always accompanied by an increase in the concentration of urea. Although the concentration curves tend to parallel one another, there is in all experiments at the 10-mU level a more rapid increase in NUS than in urea concentration at some point during the initial 10 minutes. As noted in Figures 1 and 2 , the duration of hormone effect was shorter with the lower doses, particularly with $10 \mathrm{mU}$. Observations were extended over comparable time periods after all dosages, however, to insure detection of the maximal vasopressin effect.

The hypothesis has been formulated that the permeability of the distal nephron might be evaluated by determining the degree to which the tubule discriminates between urea and NUS after the rapid initiation of vasopressin action in the kidney. This hypothesis has been tested by conducting numerous experiments at varying doses of vasopressin and thus imposing varying degrees of permeability on the renal tubules. To evaluate

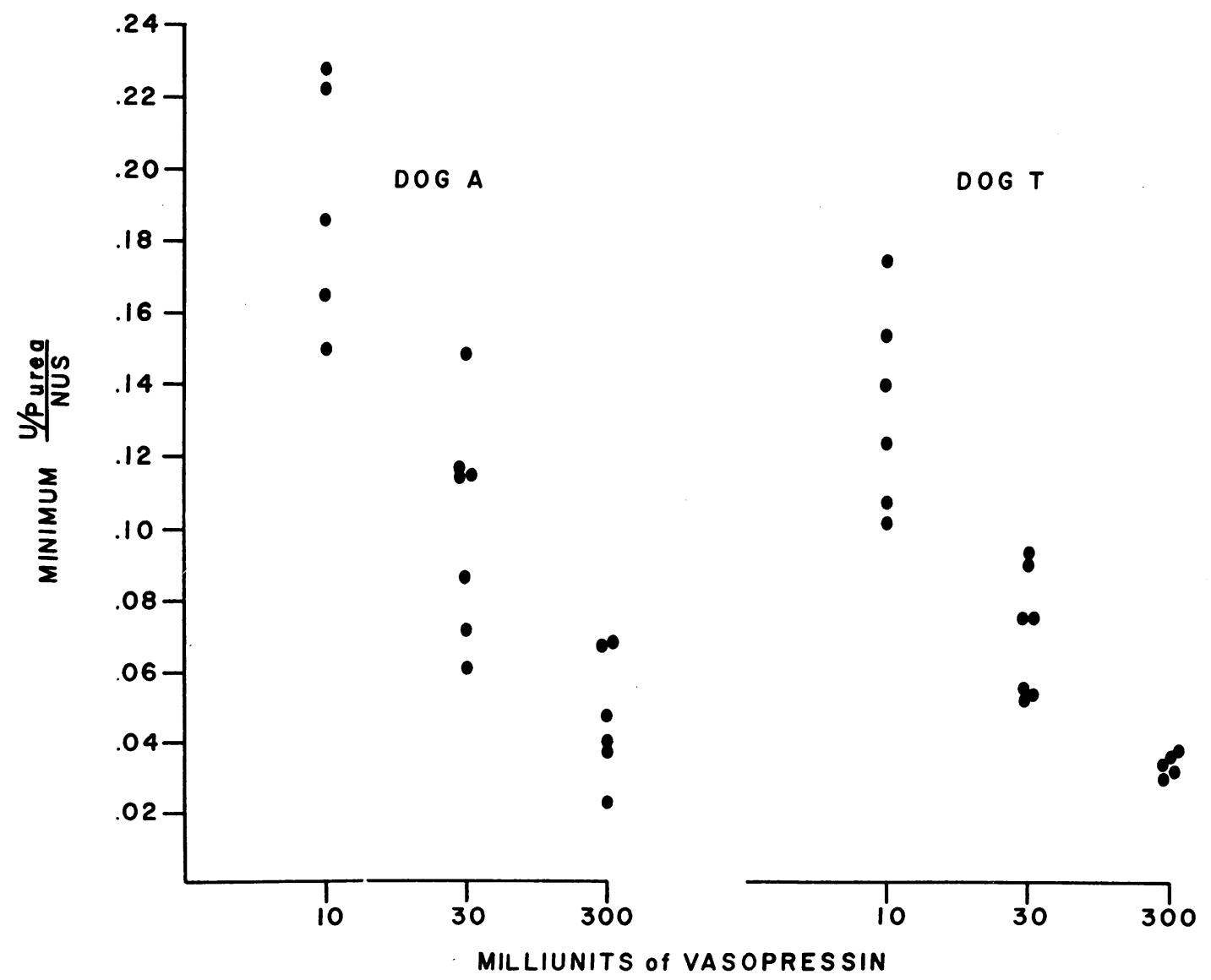

Fig. 3. Minimum U/Purea/NUS ratio at various dosage levels of vasopressin. Results of thirty-six experiments in two dogs. 


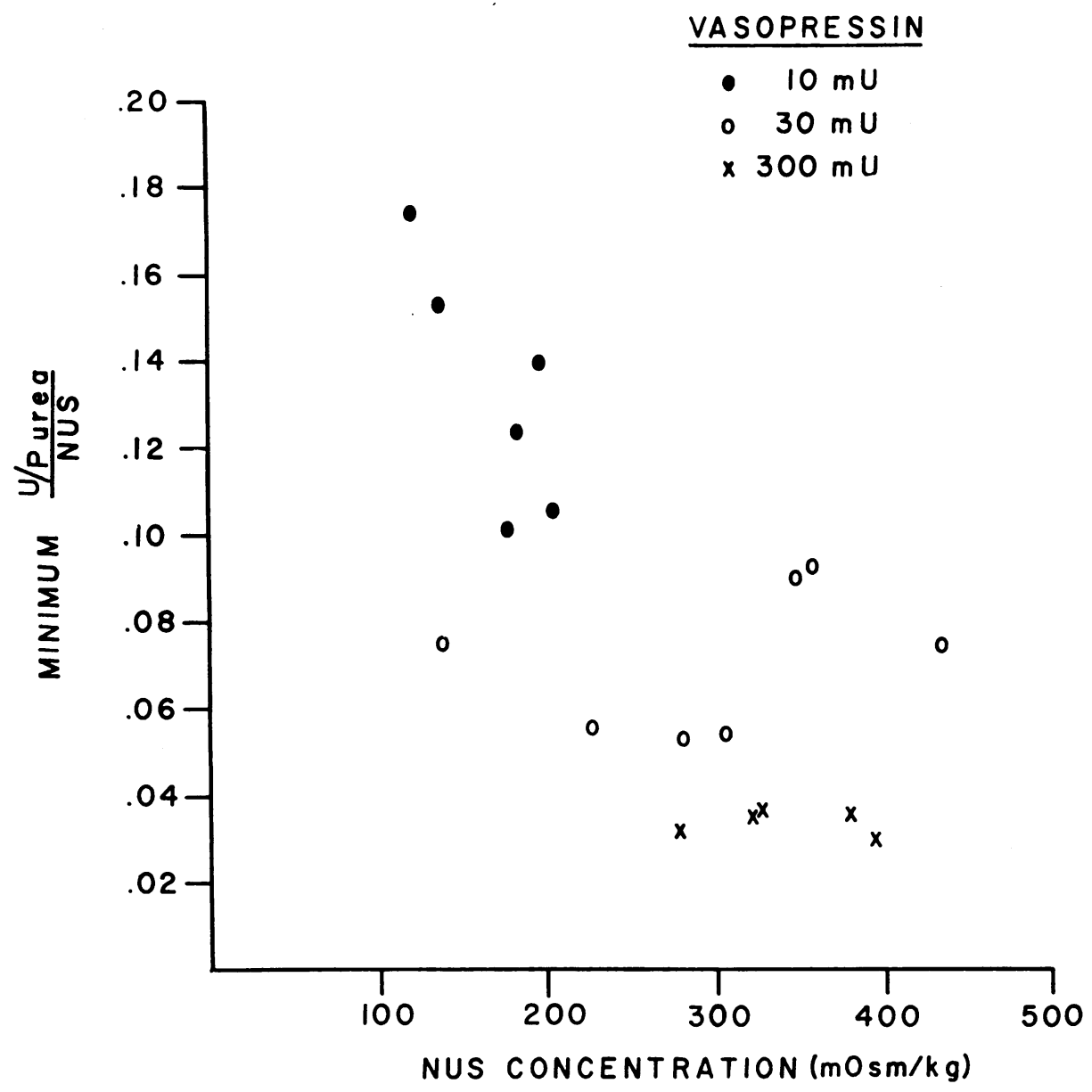

Fig. 4. Dog T. EFFect of NUS concentration of the URINe on the Minimal U/Purea/ NUS RATIO AT VARIOUS DOSES OF VASOPRESSIN.

and compare these experiments, the qualitative differences in response to differing amounts of hormone have been analyzed quantitatively. It is apparent from Figures 1 and 2 that the ratio of urea to NUS concentration decreases after vasopressin administration and reaches some minimal value, after which it increases as the urinary urea concentration rises. To eliminate the effect of variations in the plasma urea concentration, the urine to plasma concentration ratio for urea has been utilized, leading to the calculation of the $\mathrm{U} / \mathrm{P}$ urea ratio divided by the urinary NUS concentration. The latter has not been corrected for the plasma NUS concentration, since this term is virtually identical from one experiment to the next. The resulting ratio, $\mathrm{U} / \mathrm{P}_{\text {urea }} / \mathrm{NUS}$, is an arbitrary value but one that does reflect the renal tubule's degree of discrimination between these molecular species. As indicated in Table I, this ratio has been calculated for each collection period in all experiments. The relationship between the minimal ratio observed in each experiment and the dosage of vasopressin is shown in Figure 3. This ratio tends to be inversely related to the dosage of vasopressin, with minimal overlap of values between adjacent dosage levels.

Since a ratio of two values has been utilized to evaluate the results of these studies, it seems necessary to determine whether the lower ratios observed after administration of $300 \mathrm{mU}$ of vasopressin were primarily the result of a higher urinary NUS concentration at this dosage level. For this purpose the minimal $U / \mathrm{P}_{\text {urea }} / \mathrm{NUS}$ value for each experiment has been plotted against the NUS concentration of the urine at the time this minimal value was observed. These data are shown in 
Figures 4 and 5 for dogs $\mathrm{T}$ and $\mathrm{A}$, respectively. The plots clearly show that the difference in the ratios observed at the 30 - and $300-\mathrm{mU}$ dosage levels cannot be accounted for by a higher NUS concentration consequent to administration of 300 $\mathrm{mU}$, since in the majority of $30-\mathrm{mU}$ experiments the NUS concentrations were in the same range as that observed with the higher hormone dosage. In most instances a lower NUS concentration was present at this point in the $10-\mathrm{mU}$ experiments, although there is overlap with the higher doses, particularly in dog A (Figure 5). This difference between the $10-\mathrm{mU}$ and other dose levels is reduced, however, by a plot of the minimal ratio against total urinary osmolality, since in the $10-\mathrm{mU}$ experiments a larger fraction of the total urinary solutes is accounted for by urea, thus yielding low
NUS concentrations relative to total urinary osmolality.

The experiments reported above were conducted during water diuresis, without the imposition of exogenous solute loads. Within the limits of endogenous solute excretion observed in these animals, no effect of the rate of solute excretion on the minimal $U / \mathrm{P}_{\text {urea }} / \mathrm{NUS}$ ratio was apparent. Solute excretory rates during water diuresis immediately preceding vasopressin administration ranged from 195 to $411 \mu$ Osm per minute in $\operatorname{dog} \mathrm{T}$ and from 158 to $246 \mu$ Osm per minute in $\operatorname{dog}$ A. Similarly, at each dosage level of vasopressin, the minimal ratio achieved bore no relationship to the clearance of inulin in the periods immediately preceding hormone administration.

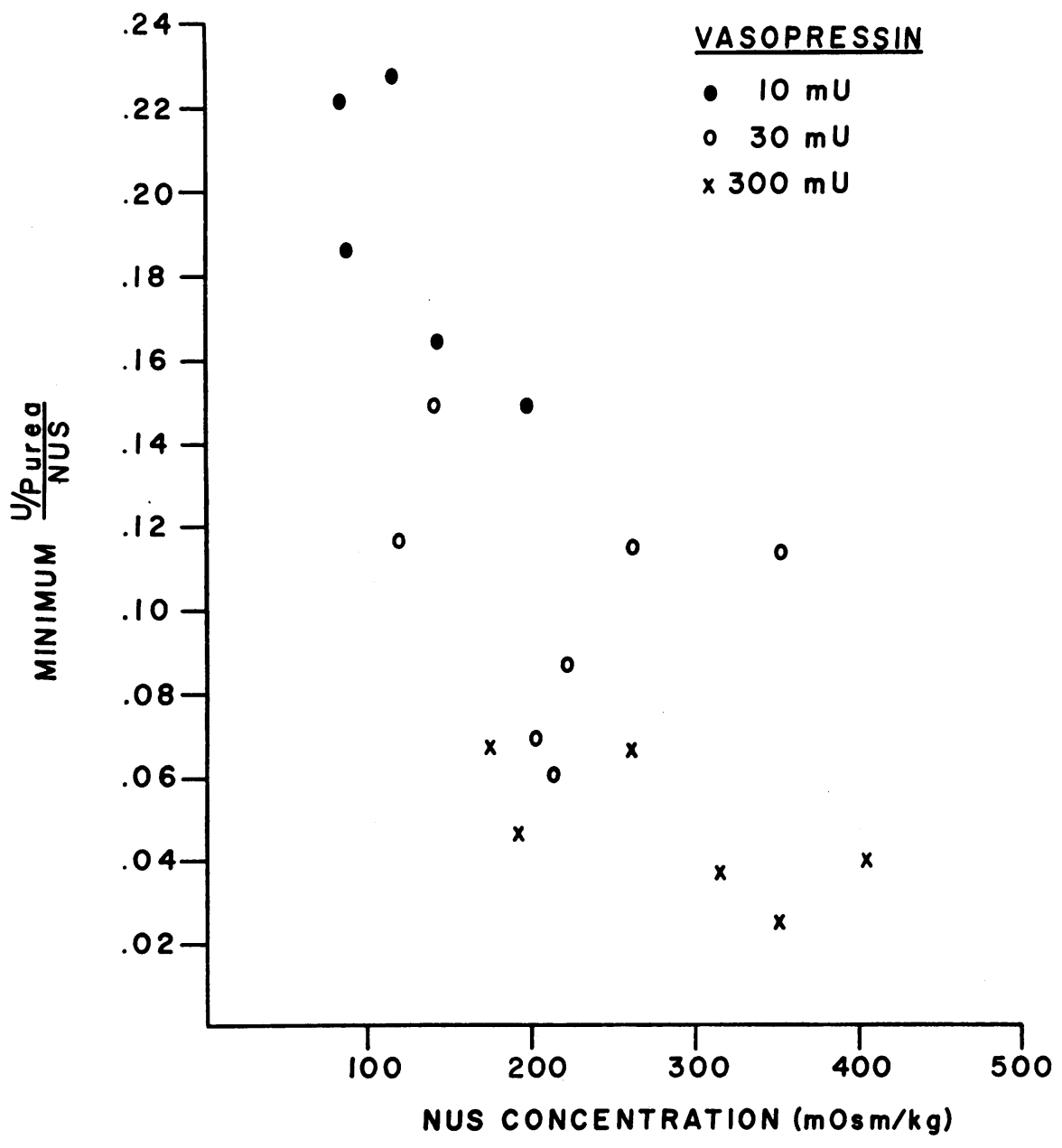

Fig. 5. Dog A. EFfect of NUS concentration of the URINe on the Minimal U/Purea/NUS RATIO AT VARIOUS DOSES OF VASOPRESSIN. 


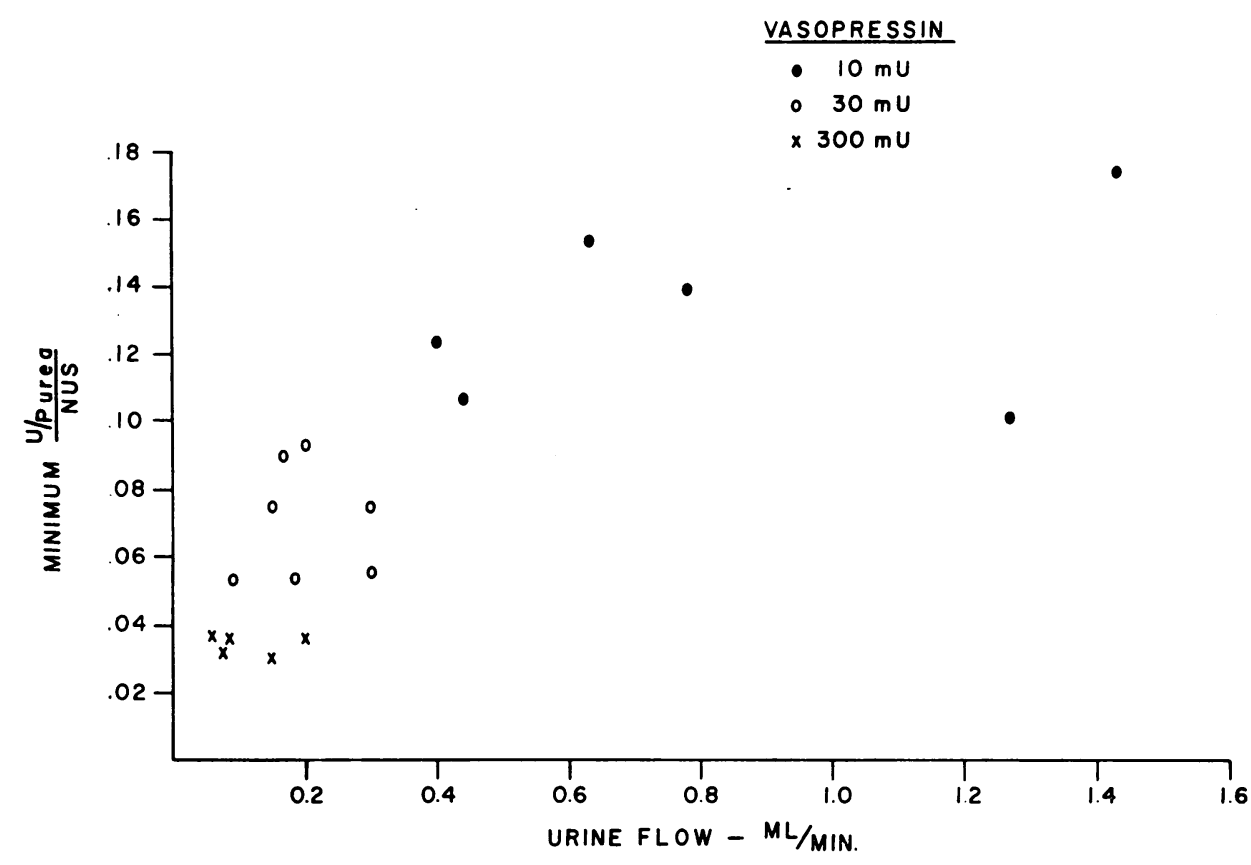

Fig. 6. Dog $T$. EFfect of URINARy flow rate on minimal U/Purea/NUS Ratio at various DOSES OF VASOPRESSIN.

The rate of urea excretion or clearance tends to be directly related to the urinary flow rate (5). Consequently, the influence of flow on the minimal $U / P_{\text {urea }} / \mathrm{NUS}$ ratio has been examined. These data, the minimal ratio against the flow rate in the collection period in which this ratio was attained, are plotted in Figures 6 and 7 . These plots reveal that flow tends to be inversely related to the dosage of vasopressin. There is essentially no correlation between the minimal ratio and the flow rate within each group of experiments at a given hormone dosage, with the possible exception of the $30-\mathrm{mU}$ experiments in dog A (Figure 7 ), in which the two lowest ratios were associated with the lowest flow rates in this group. There is considerable overlap of flow rates between certain of the dosage groups, particularly the 30 - and $300-\mathrm{mU}$ groups in dog $\mathrm{T}$ (Figure 6 ) and the $10-$ and 30-mU groups in $\operatorname{dog} \mathrm{A}$ (Figure 7). This overlap, and the lack of correlation between ratio and flow at a given hormone dosage, indicate that the relationship between the $U / \mathrm{P}_{\text {urea }} / \mathrm{NUS}$ ratio and the dosage of vasopressin is not due simply to an effect of the hormone on the urinary flow rate. Increased reabsorption of urea from the distal nephron will in itself reduce the rate of solute excretion and consequently the rate of flow under the conditions of these experiments, since urea constitutes the major fraction of the total urinary solute during water diuresis, immediately before hormone administration.

Experiments conducted during solute diuresis coincident with water diuresis reveal a less striking difference between the initial rates of rise of urea and NUS after vasopressin administration. Figure 8 presents data from an experiment during combined mannitol and urea diuresis. Solute was infused in amounts calculated to yield approximately equal urinary concentrations of urea and NUS at zero time. Following $300-\mathrm{mU}$ dosage of vasopressin there is, between one-half and $3 \frac{1}{2}$ minutes, a distinctly more rapid rise in urinary NUS than in urea concentration, but this difference is less marked than that observed in simple water diuresis (Figures 1 and 2). The initial lag in the rise of urea concentration is absent in experiments performed during combined solute and water diuresis. Similar results have been obtained when mannitol or urea was infused alone.

\section{Discussion}

The administration of vasopressin during water diuresis evokes a rapid increase in urinary osmolality, resulting from the osmotic abstraction 
of water from the distal nephron. The efflux of water will tend to increase the intratubular concentration of urea. However, in experiments utilizing $300 \mathrm{mU}$ of vasopressin, there is little or no increase in urinary urea concentration associated with the initial rise in urinary NUS or inulin concentration. This observation is indicative of a rapid efflux of urea during this period.

In contrast to the studies employing $300 \mathrm{mU}$ of vasopressin, when submaximal doses are given, the urinary urea concentration tends to rise initially, concomitant with efflux of water from the tubular lumen. The tendency for the rise of urea concentration to parallel that of NUS is inversely related to the dose of vasopressin.
These observations tend to confirm the hypothesis that varying degrees of tubular permeability, produced by administration of graded doses of vasopressin, will be manifested by relative differences in the degree to which urea and water will permeate the epithelial membrane of the distal nephron. Clearly a number of variables that may influence the relative rates of urea and water efflux from the distal nephron cannot be evaluated in the intact kidney. Perhaps the most important of these are the urea and osmotic gradients between lumen and peritubular space, particularly in the renal medulla. By superimposing the rapid administration of vasopressin on water diuresis and determining the initial changes in urinary

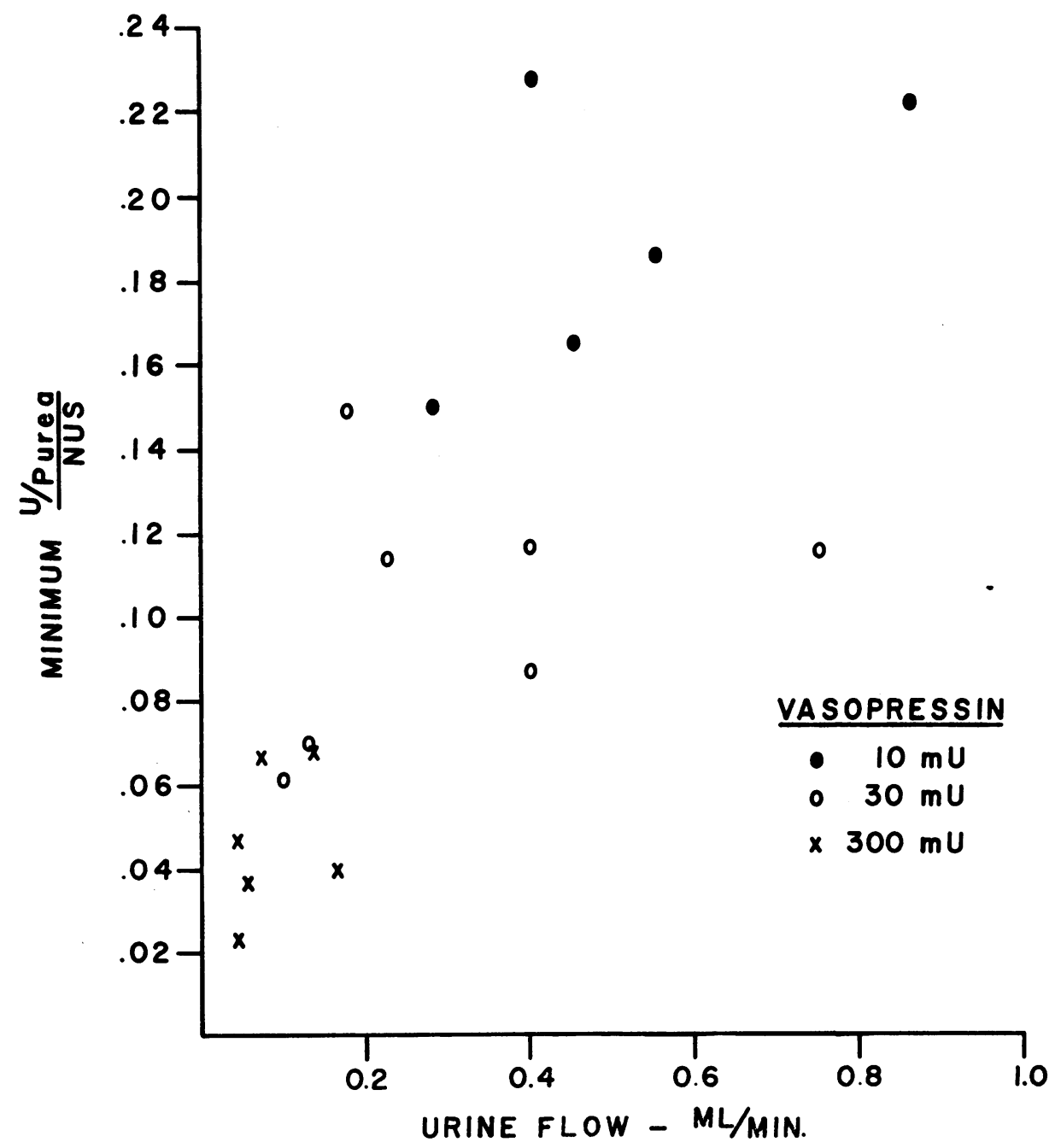

Fig. 7. Dog A. Effect of URinary flow rate on minimal U/Purea/NUS ratio at various DOSES OF VASOPRESSIN. 


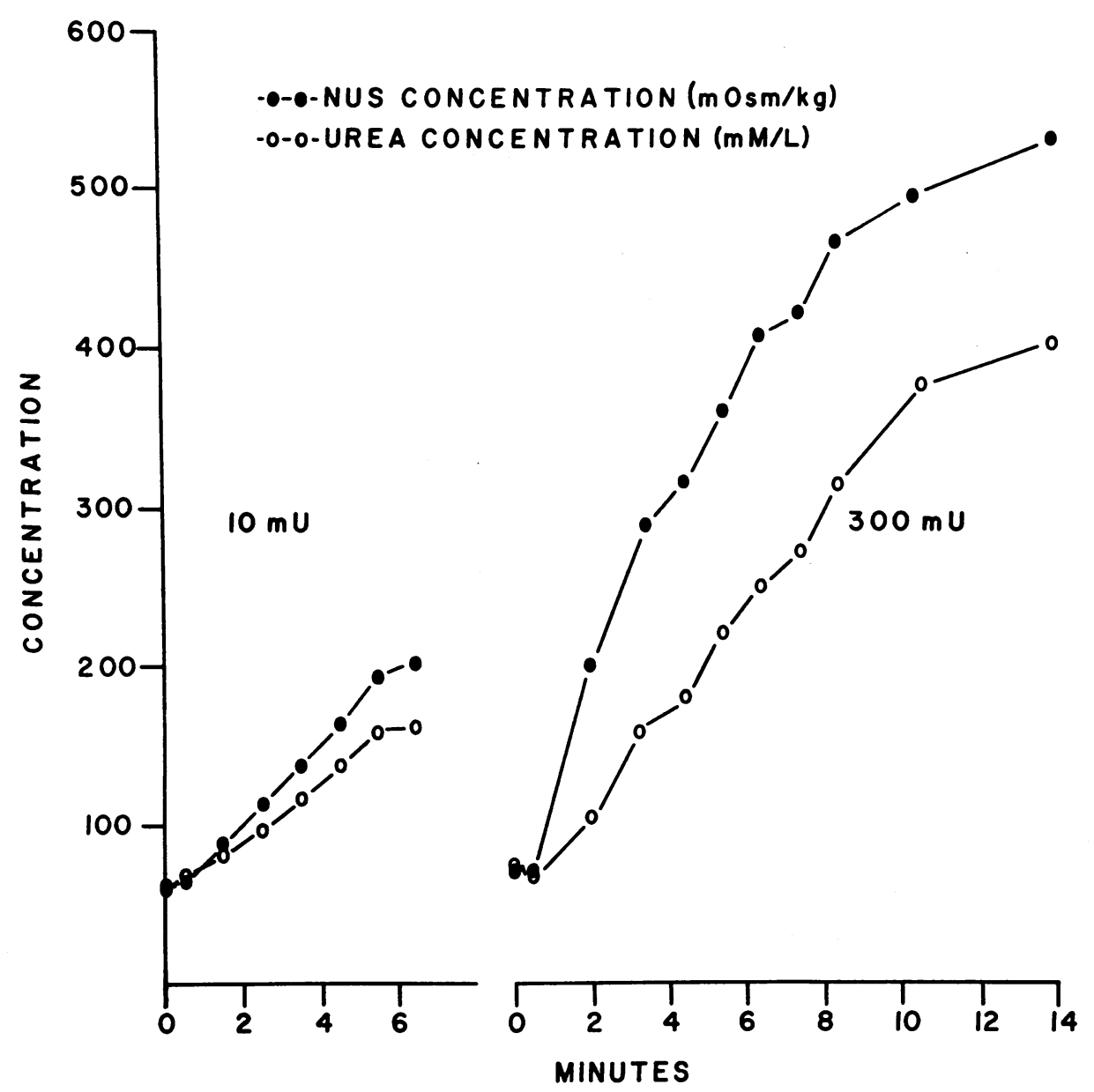

Fig. 8. Dog T. Rates of rise of urea and NUS AFter 10 and 300 mU of vasopressin ADMINISTERED DURING COMBINED SOLUTE (UREA PLUS MANNITOL) AND WATER DIURESIS. Rates of solute excretion at zero time: $670 \mu \mathrm{Osm}$ per minute in 10-mU experiment, $840 \mu \mathrm{Osm}$ per minute in 300-mU experiment. Infusion: 74 mmoles per $\mathrm{L}$ mannitol, 150 mmoles per $\mathrm{L}$ urea, and $20 \mathrm{mEq}$ per $\mathrm{L} \mathrm{NaCl}$, in $2 \%$ glucose solution at $6.0 \mathrm{ml}$ per minute.

composition, certain of these variables may be minimized. At zero time the respective urea and osmotic gradients will be independent of the subsequent dose of vasopressin, so that subsequent changes in urinary composition may be attributed to the effects, direct or indirect, of the hormone. Aside from its acknowledged influence on membrane permeability, evidence suggests that vasopressin may augment the medullary sodium gradient (6) and decrease the rate of medullary blood flow (7). The latter effect would tend to increase the efficiency of urea trapping in the medulla (8) and therefore cannot readily be invoked to explain the apparent increase in urea efflux observed with high doses of hormone. Variation in the rate of distal water reabsorption after vasopressin administration may affect the rate of efflux of urea relative to that of water and might be invoked to explain the differences between varying doses of hormone. The data, however, indicate comparable initial rates of distal water reabsorption in the 30 - and $300-\mathrm{mU}$ experiments, suggesting that the differences in the urinary urea concentration curves during this time are at least partially independent of this variable. As discussed below, other evidence suggests that the rate of urea delivery to the distal nephron may influence the results of these experiments. Despite these variables that cannot be assessed directly, the present study suggests that information 
regarding the permeability of the distal nephron may be obtained from this experimental approach.

The data in this paper appear to bear on the means for the achievement of a high medullary concentration of urea during the antidiuretic state. According to most current evidence, urea enters the medulla of the dog kidney by movement along its chemical gradient from the lumen of the collecting duct $(2,9)$. A high medullary urea content is attained only in the presence of a high concentration of urea in collecting duct fluid, the latter resulting from osmotic abstraction from the tubule of water as it descends the medulla $(9,10)$. The movement of urea relative to that of water out of the collecting duct must be restrained for a high intratubular concentration of urea to become established. It has been inferred that this process results from a significant restriction of urea permeation in the collecting duct, due to this epithelial membrane's permeability characteristics (2). The present data, however, suggest a high degree of permeability to urea in the distal nephron. After administration of $300 \mathrm{mU}$ of vasopressin, urea efflux is sufficiently rapid that its intratubular concentration may decline despite a marked rise in urinary inulin concentration. This efflux must occur at a relatively small chemical gradient for urea, i.e., a gradient that cannot exceed the intraluminal concentration. These observations indicate that, under conditions of maximal permeability and low urinary flow rate, urea must closely approach diffusion equilibrium between lumen and interstitium. The data suggest that the primary factor responsible for the rise in urea concentration along the course of the collecting duct (10) is the countercurrent flow of the vasa recta $(8,11)$. I suggest that the latter mechanism acts to restrain efflux of urea from the collecting duct lumen by trapping diffused urea in the medullary interstitium, eradicating the gradient necessary for further diffusion. This gradient will be re-established only as water abstraction from the lumen raises the intratubular concentration of urea. In this manner a progressive rise in the concentration of urea within the tubule and the medullary interstitium is accomplished until a steady state is achieved (4). I also suggest that the late rise in urinary urea concentration after the administration of $300 \mathrm{mU}$ of vasopressin may be an expression of this phenomenon, although, as mentioned previously (4), the possibility exists that permeability to urea decreases after the initial transitory state following hormone injection.

The above hypothesis is in accord with the effect of the countercurrent exchanger in concentrating substances added to the medullary interstitial space (8). Ullrich, Kramer, and Boylan's formulation indicates that the countercurrent medullary blood flow will establish a longitudinal gradient, from outer medulla to the papillary tip, for molecules entering the interstitium at a rate that is uniform along the long axis of the medulla. This type of longitudinal gradient in the medulla is that observed for urea in the antidiuretic kidney $(9,12)$.

During combined solute and water diuresis, the discrepancy between the initial rates of rise of urea and NUS after injection of $300 \mathrm{mU}$ of vasopressin is considerably less marked than during water diuresis alone. This finding may be explained by the high urinary flow rate and rapid transit through the collecting duct, with resultant failure of urea to reach diffusion equilibrium. It has been suggested previously, however, that flow rate is not the primary determinant of the concentration patterns after vasopressin administration. An alternative explanation for the effect of solute diuresis arises from the consideration that only a finite amount of urea may be added to the medullary interstitium before its urea concentration rises to approach that in the tubular lumen, thus retarding further efflux of urea. During solute diuresis a high rate of delivery of urea to the medulla may result in a rapid initial rise in the interstitial urea concentration, leading to an equally rapid increase in the intratubular concentration. Two lines of evidence support this explanation for the findings during solute loading: 1) Despite higher urinary flow rates, the rate of rise of NUS relative to urea is higher in certain 10-mU experiments during water diuresis than in the $300-\mathrm{mU}$ experiment during mannitol and urea infusion depicted in Figure 8. 2) Previous experiments during low protein feeding, with resultant low rates of urea delivery to the distal nephron, revealed a very prolonged lag in the initial concentration rise of urea following vasopressin administration (4) (Figure 4). These 
observations suggest that large differences in the rate of urea delivery to the distal nephron may influence considerably the relative concentration patterns of urea and NUS following vasopressin administration.

\section{Summary}

Studies have been conducted in unanesthetized dogs during the acute transition from water diuresis to antidiuresis, induced by the rapid administration of lysine vasopressin. Attention has been directed primarily to the concentration patterns of urea and of nonurea solutes in the urine during this transitory state. The effect of variations in tubular permeability on these concentration patterns has been evaluated by administering graded doses of vasopressin, 10, 30, and $300 \mathrm{mU}$, in separate experiments.

Following the highest dose of vasopressin, there occurs an initial rise in urinary nonurea solute concentration, which is not associated with a concomitant increase in urea concentration. This is interpreted as indicating a high degree of discrimination between these molecular species under conditions of maximal tubular permeability. Studies utilizing submaximal amounts of hormone suggest that the ability of the tubule to exercise this discrimination is directly related to the degree of tubular permeability, or the dosage of vasopressin. These observations suggest a method for the evaluation of membrane permeability in the distal nephron of the intact animal.

The apparent high degree of permeability to urea of the distal nephron in the presence of maximal amounts of vasopressin suggests that trapping of urea, by the vascular countercurrent exchanger in the medulla, may be the primary means by which a high concentration of urea is achieved within the distal collecting duct, and ultimately the medullary interstitium, in the antidiuretic state.

\section{Acknowledgment}

The author is grateful to Mrs. Linda Blann and Miss Shirley Hendershot for their able technical assistance.

\section{References}

1. Maffly, R. H., R. M. Hays, E. Lamdin, and A. Leaf. The effect of neurohypophyseal hormones on the permeability of the toad bladder to urea. J. clin. Invest. 1960, 39, 630.

2. Jaenike, J. R. The influence of vasopressin on the permeability of the mammalian collecting duct to urea. J. clin. Invest. 1961, 30, 144.

3. Gardner, K. D., Jr., and R. H. Maffly. The effect of vasopressin on rat collecting tubule permeability to urea studied in vitro. Clin. Res. 1963, 11, 241.

4. Jaenike, J. R. Acute effects of the administration of vasopressin during water diuresis in the dog. $\mathrm{J}$. clin. Invest. 1963, 42, 161.

5. Shannon, J. A. Glomerular filtration and urea excretion in relation to urine flow in the dog. Amer. J. Physiol. 1936, 117, 206.

6. Levitin, H., A. Goodman, G. Pigeon, and F. H. Epstein. Composition of the renal medulla during water diuresis. J. clin. Invest. 1962, 41, 1145.

7. Thurau, K., P. Deetjen, and K. Kramer. Hämodynamik des Nierenmarks. II. Wechselbeziehung zwishen vasculärem und tubulärem Gegenstromsystem bei arteriellen Drucksteigerungen, Wasserdiurese und osmotischer Diurese. Pflügers Arch. ges. Physiol. 1960, 270, 270.

8. Ullrich, K. J., K. Kramer, and J. W. Boylan. Present knowledge of the counter-current system in the mammalian kidney. Progr. cardiovasc. Dis. 1961, 3, 395.

9. Levinsky, N. G., and R. W. Berliner. The role of urea in the urine concentrating mechanism. J. clin. Invest. 1959, 38, 741.

10. Klumper, J. D., K. J. Ullrich, and H. H. Hilger. Das Verhalten des Harnstoffs in den Sammelrohren der Säugertierniere. Pflügers Arch. ges. Physiol. 1958, 267, 238.

11. Berliner, R. W., N. G. Levinsky, D. G. Davidson, and M. Eden. Dilution and concentration of the urine and the action of antidiuretic hormone. Amer. J. Med. 1958, 24, 730.

12. Ullrich, K. J., and K. H. Jarausch. Untersuchungen zum Problem der Harnkonzentrierung und Harnverdünnung. Pflügers Arch. ges. Physiol. 1956, 262, 537. 